\title{
Mudanças sociais e saberes: o papel da educação na terceira idade
}

\author{
Rita de Cássia Oliveira*, Paola Andressa Scortegagna*, Flávia da Silva Oliveira**
}

\section{Resumo}

As pessoas na terceira idade têm muito para ensinar, porém ainda tem muito a aprender, demonstrando a necessidade de estarem em contato com novos conhecimentos e, também, com novas experiências. Os idosos possuem o direito à educação, previsto no capítulo V, artigos 20 a 25, do Estatuto do Idoso (lei $n^{0} 10741 / 2003$ ). Dessa maneira, a presente pesquisa tem por objetivo identificar o papel da educação como possibilidade de mudanças para os idosos; analisar as diferentes formas de inserção e integração do idoso no contexto educativo; analisar as políticas públicas destinadas ao direito do idoso à educação. A pesquisa é quanti-qualitativa e utilizou a observação e aplicação de questionários com alunos da Universidade Aberta para a Terceira Idade da UEPG para coleta de dados. Como resultados, foi possível observar que uma ação educacional consciente permite mudanças e transformações na vida dos idosos, possibilitando uma melhor qualidade de vida. Também, as políticas públicas voltadas para esse segmento devem propiciar direitos nos diferentes âmbitos, como a saúde, lazer, esporte e a educação.

Palavras-chave: Idoso. Políticas públicas. Educação continuada.

\section{Introdução}

No momento atual, a terceira idade encontra-se em grande evidência nas discussões da sociedade brasileira. No âmbito social, como também na própria esfera familiar, enfatizam-se relações de discriminação, preconceito e marginalização com essa faixa etária. Nota-se que a preocupação com esta população está num ritmo crescente, uma vez que

* Pedagoga. Gerontóloga. Doutora em Ciências da Educação pela Universidade de Santiago de Compostela. Professora Associada do Departamento de Educação e professora Permanente do mestrado em Educação na Universidade Estadual de Ponta Grossa. Coordenadora da Universidade Aberta para a Terceira Idade da Universidade Estadual de Ponta Grossa. Endereço para correspondência: Rua Padre João Lux, 686, ap ${ }^{\text {to }}$ 61, Centro, Ponta Grossa - PR. CEP 84010-045. E-mail: soliveira13@uol.com.br

** Pedagoga. Mestra em Educação pela Universidade Estadual de Ponta Grossa. Professora da Universidade Aberta para a Terceira Idade da Universidade Estadual de Ponta Grossa.

**** Advogada. Mestra em Ciências Sociais Aplicadas pela Universidade Estadual de Ponta Grossa. Coordenadora e professora do curso de Direito da Faculdade União. Professora da Universidade Aberta para a Terceira Idade da Universidade Estadual de Ponta Grossa.

$\longrightarrow$ Recebido em novembro de 2008 - Avaliado em março de 2010.

$\rightarrow$ doi:10.5335/rbceh.2009.037 
a demanda social aumenta em razão do crescimento e envelhecimento da população brasileira, a qual segue a tendência mundial.

Diante dessa realidade, na qual o Brasil apresenta hoje cerca de $16 \mathrm{mi}-$ lhões de idosos, representando $9,7 \%$ da população, destacam-se diferentes iniciativas públicas e privadas para oferecer alternativas educacionais a esses com o intuito primeiro de possibilitar uma maior inserção social. Percebe-se que o Brasil está envelhecendo, dado que está presente nos censos demográficos no que se refere ao envelhecimento populacional.

Porém, observa-se que há a tendência de sublimar uma vida depois dos sessenta, não a valorizando, como também se exclui a possibilidade de realizar muitos desejos e expectativas, além de se rejeitar a subjetividade dessas pessoas.

Considerando essas questões, notase que o próprio termo "velho" já traz consigo um grande conjunto de conotações pejorativas. Em uma sociedade que idolatra a juventude, a beleza, ser velho significa estar em um universo de rejeição e exclusão. Para que seja possível reverter esse quadro, ocorre a implantação de políticas de atendimento ao idoso, tendo como objetivo maior evitar o seu isolamento social.

A conscientização de que o idoso de décadas atrás não é o mesmo de hoje necessita ser assimilada por todos, principalmente jovens e adultos. Antigamente, a maioria dos idosos possuía pouco conhecimento científico sistemático, ao passo que os idosos do século XXI têm maior nível de escolaridade, inclusive muitos têm graduação, curso superior. Logo, suas necessidades e anseios são outros e precisam ser supridos da melhor maneira possível.

Já passou o tempo em que envelhecer era sinônimo de ficar em casa. $\mathrm{O}$ avanço da idade não reprime qualquer capacidade do indivíduo; é apenas uma questão de adaptação às novas limitações, principalmente do corpo.

"Se as condições sociais continuarem a melhorar no mundo, diminuindo a mortalidade precoce, a população mais velha aumentará ainda mais do que o crescimento das coortes de nascimento poderia fazer prever." (VERAS apud BACELAR, 2002, p. 33). Dessa perspectiva, pode-se afirmar que a população idosa tende a aumentar, sendo necessário investir em políticas públicas voltadas para uma melhor qualidade de vida, além de propiciar uma educação permanente para essas pessoas, com o objetivo de possibilitar um processo de atualização e interação.

Hoje, a educação na terceira idade volta-se para um âmbito diferenciado, não mais sendo um meio de assistencialismo aos envolvidos. Nota-se um novo enfoque, pois o idoso não é apenas uma pessoa que necessita de atividades recreativas para ocupar seu tempo, mas, sim, precisa de espaço para crescer sempre.

Percebe-se, então, que a educação possui um caráter de transformação, ultrapassando a mera ideia de transmissão de informações. Nesse sentido, parafraseando Piconez (2002), a educação instrumentaliza crítica e criativamente, tendo em vista a inovação da realidade. Dessa maneira, observa-se o quanto o processo educativo permite um estágio 
de mudanças, independentemente da idade.

O processo de mudança desejada representa um longo caminho a ser percorrido. No entanto, se o primeiro passo não for dado, nunca se efetivará a transformação almejada. Portanto, o professor deve ser um dos precursores do processo de geração de mudanças, já que é ele quem participa efetivamente do processo educacional.

Nesse âmbito, "os velhos precisam de um espaço de fala que torne possível uma ressignificação de seu eu. Algo que lhes permita relançar o desejo e manter o olhar sobre si". (CASTRO, 2001, p. 68). Dessa maneira, a educação é um importante meio de transformação e valorização do idoso.

Nota-se que, quando a educação se torna permanente na vida dos idosos, é possível encontrar um novo sentido de viver, mesmo quando eles já se encontram desacreditados pela própria sociedade. A educação é vista como um meio de libertação e mudanças na terceira idade, pois permite a reavaliação das características próprias, além de propiciar um processo de análise e reflexão para essas pessoas.

A conscientização de que todos chegarão à terceira idade é um fator fundamental no quadro evolutivo da aceitação dos idosos na sociedade. Mas não basta aceitá-los. Eles precisam reconhecer seu espaço e sua importância nesse meio. Façamos uma relação: a criança, quando inicia seu processo de socialização formal, encontra na escola essa oportunidade. É um espaço aberto, com profissionais preparados e dispostos a recebê-la. Então, que esse mesmo espaço educacional esteja aberto para a terceira idade se reencontrar na sociedade.

Em muitos casos, o idoso necessita da escola para se aprimorar ou simplesmente encontrar um sentido para sua vida. Todos nós precisamos de uma "figura especial que nos ajude a descobrir dimensões mais profundas e a escolher nossos caminhos com maior liberdade". (ALBOM, 1998). Certamente, a presença de educadores nessa etapa da vida só vem a acrescentar. Esses educadores têm as condições de serem fundamentais na vida de todas as pessoas, principalmente dos idosos.

As oportunidades que temos durante nossa vida nos ajudam a formar ideias e aceitar com maior clareza os acontecimentos naturais. Nesse contexto,

à medida que se cresce, aprende-se mais. Se ficássemos parados nos vinte e dois anos, ficaríamos sempre ignorantes como quando tínhamos vinte e dois anos. Envelhecer não é só decair fisicamente. É crescer. É mais do que o fato negativo de que se vai morrer, é também o fato positivo de que se compreende que se vai morrer e que se pode viver melhor por causa disso. (ALBOM, 1998, p. 117).

O importante é, sem dúvidas, conscientizar-se de que há muito para se fazer na terceira idade, muito para crescer. A sociedade, como um todo, inicia um processo de significação para essa etapa da vida. Há muito para se fazer, para compreender. Mas atualmente já olhamos para com outros olhos para os idosos e para toda sua contribuição.

Contudo, percebe-se que as políticas públicas de inserção do idoso num âmbito educacional muitas vezes são relegadas a segundo plano pelo desconhecimento, falta de financiamento ou 
até mesmo pela falta de amparo legal que fundamente a educação para a terceira idade.

Parafraseando Oliveira (1999), hoje a terceira idade está sendo significativamente considerada no país como uma das questões da problemática social, pois ocorre um processo de envelhecimento em ritmo acelerado se comparado com o de países desenvolvidos. Nesse contexto, observa-se que ainda há a tendência de sublimar uma vida depois dos sessenta, não a valorizando, como também se exclui a possibilidade de se realizarem muitos desejos e expectativas, além de se rejeitar a subjetividade de cada uma dessas pessoas.

É preciso rever como o idoso está sendo percebido e aceito na sociedade, como presenciando essas mudanças no espaço político-social e em sua própria vida. Com base nessa análise, torna-se pautável compreender como a educação poderá influenciar esse quadro vivenciado em nossa sociedade há muitos anos.

Apesar de a questão do idoso não ser nova, pois na década de 1980 o próprio Congresso realizou alguns eventos e debates acerca do envelhecimento, ainda não recebeu o destaque merecido, porque algumas iniciativas das décadas de 1970 e 1980 foram pouco divulgadas. Observam-se nessas décadas algumas legislações voltadas ao assistencialismo ao idoso, porém em situações isoladas (lei $\mathrm{n}^{\circ} 6179 / 1974$, amparo previdenciário ao idoso, e decreto $\mathrm{n}^{\circ} 86.880$, de 1982 , que instituiu 1982 como "Ano Nacional do Idoso"). É importante destacar e divulgar a lei federal $\mathrm{n}^{\circ} 8.842 / 94$, que implantou a Política Nacional do Idoso e criou o
Conselho Nacional do Idoso, como também a lei $\mathrm{n}^{\circ} 10741 / 2003$, que instituiu o Estatuto do Idoso.

Segundo Freire (1979, p. 27), “a educação é uma resposta da finitude da infinitude", pois o sujeito é incompleto, e encontra nos processos educacionais pressupostos para suprir sua constituição pessoal inacabada, independentemente de sua idade ou situação social.

Torna-se necessário, antes de compreender a inserção do idoso num contexto educacional, refletir sobre o processo de envelhecimento e a velhice, sabendose que "o envelhecimento proporciona variedade e riqueza de experiências psico-sociais e reacionais." (MORAGAS, 1991, p. 124).

As definições de velhice apresentamse como resultantes da diversidade de enfoques existentes e convergem em torno de denominadores comuns, revestidos do entendimento de diferentes estudiosos sobre os fatores relevantes de tal definição, entre os quais se podem citar os cronológicos, biológicos, psicológicos, sociais e espirituais. Assim, torna-se indispensável a abordagem de múltiplos e diferentes critérios que incidem sobre a caracterização do que é velhice.

Moragas (1991, p. 54) destaca que "muita gente se surpreende ao comprovar que pessoas idosas desempenham atividades físicas e intelectuais com plena efetividade". Mas percebe-se que na sociedade brasileira, geralmente, convive-se com um conceito pejorativo da velhice, acrescido do descaso geral com relação a essa faixa etária. Há a desconsideração da capacidade de produção e de aprendizagem para a terceira idade. 
O problema do envelhecimento também é pouco contemplado na Constituição Federal (art. 230). Em face aos problemas decorrentes da longevidade, elaborou-se a lei $\mathrm{n}^{\circ} 8.842$, de 4 de janeiro de 1994, que implantou a Política Nacional do Idoso e estabeleceu aspectos relevantes que a sociedade reivindica do governo desde os meados da década de 1970. Essa lei surgiu em virtude de inúmeras pressões da sociedade brasileira e da influência do documento "Política para Terceira Idade nos anos 90", produzido pela Associação Nacional de Gerontologia (ANG), que contemplou um rol de recomendações para essa faixa etária.

Segundo Fernandes (1999, p. 20), trata-se de uma lei especial que procura valorizar a qualidade de vida e a longevidade, ao mesmo tempo em que estabelece recomendações para que as pessoas idosas sejam entendidas e desfrutem de vida plena e saudável, segura e satisfatória, junto de suas famílias e na comunidade onde vivem.

Dessa maneira, o papel da educação nessa realidade torna-se fundamental, pois é por meio dela que as heranças culturais presentes em nossa realidade poderão se modificar no pensamento da nossa população. Assim, ressalta-se que "a educação é o processo pelo qual a sociedade forma seus membros à sua imagem e em função de seus interesses". (VIEIRA PINTO, 1989, p. 29).

Observa-se o quanto as pessoas se prendem às ideologias que permeiam todo pensamento e aspectos culturais, tornando complexo compreender esse pensamento e revertê-lo. Assim, é preciso auxiliar as pessoas nessa transfor- mação, porque apenas desta maneira será possível reverter muitos problemas sociais, em especial a exclusão e estereótipos negativos atribuídos ao idoso na sociedade brasileira. Nesse aspecto, Freire (1996, p. 110) aponta que "a educação é uma forma de intervenção no mundo".

Torna-se imprescindível rever as estruturas que permeiam a educação para que se possam redirecionar os aspectos excludentes da nossa cultura. Nesse âmbito, é preciso ressaltar o papel democrático que a educação possui assim como todas as possibilidades de mudança que podem ocorrer por seu intermédio.

Saviani (2003, p. 21) ressalta que "o processo educativo é a passagem da desigualdade à igualdade". Com base nesses considerações, percebe-se que a educação é o ponto culminante de toda a mudança no pensamento presente, para que se possa sair de uma cultura excludente para um pensar crítico e compatível com a atual realidade.

Nessa perspectiva, busca-se o entendimento da educação para a terceira idade como uma realidade que precisa ser incrementada por diferentes programas oferecidos aos idosos, possibilitando a aquisição de conhecimentos a instrumentalização desses indivíduos, a fim de propicia-lhes uma participação mais ativa e integrada na sociedade.

Quando a educação se torna permanente na vida dos idosos, é possível encontrar um novo sentido em viver, mesmo quando já se encontram desacreditados pela própria sociedade, pois "a educação na terceira idade está inserida no processo de educação permanente". (SCHONS; PALMA, 2000, p. 160). 
Vieira Pinto (1989, p. 39) afirma que "a educação não é uma conquista do indivíduo [...], mas uma função da sociedade e como tal dependente de seu grau de desenvolvimento. Onde há sociedade há educação: logo, esta é permanente".

Parafraseando Bacelar (2002), a educação é o maior instrumento no processo de reformulação das subjetividades, com efeito multiplicativo. Portanto, é vista como um meio de libertação e mudanças na terceira idade e permite a reavaliação das características próprias, além de propiciar um processo de análise e reflexão para essas pessoas.

Os idosos têm a capacidade de aprender, independentemente da sua idade. A partir do momento em que são incentivados, o processo de aprendizagem ocorre de maneira significativa. Também se torna imprescindível destacar que, além da capacidade de aprender, os idosos possuem o direito à educação, previsto no artigo 20 do Estatuto do Idoso (lei $\mathrm{n}^{\circ}$ 10741/2003).

Nas legislações referenciais à terceira idade observa-se que a educação possui destaque. No art. $3^{\circ}$ da lei $\mathrm{n}^{\circ}$ $8842 / 1994$, propõe-se a melhoria das condições de estudo para que os idosos possam aprender com mais facilidade, criando programas voltados ao idoso, além de educar a população para melhor entender o processo de envelhecimento.

Segundo o Estatuto do Idoso, no cap. 5 , art. 20, 21 e 25, o idoso tem direito à educação, respeitando a peculiar condição de sua idade. O poder público criará oportunidades de acesso do idoso à educação, havendo cursos especiais para que ele se integre à vida moderna, além de apoiar a criação de universidades abertas para as pessoas idosas e publicações de livros e periódicos com conteúdos adequados à população da terceira idade.

A Política Estadual dos Direitos do Idoso (lei estadual $\mathrm{n}^{\circ} 11.863 / 1997$ ), no título III do art. $3^{\circ}$, também destaca a adequação de currículos e programas educacionais destinados aos idosos. Esta lei pressupõe o desenvolvimento de programas que adotem modalidades de ensino a distância adequados às condições do idoso.

Por essas leis observa-se que a terceira idade tem o direito a uma educação. Entretanto, atualmente ainda se vê uma realidade distante do que se está legalmente preconizado.

$\mathrm{O}$ processo educacional deve ocorrer como ponto fundamental da socialização do idoso, uma vez que se deve constantemente buscar socializar-se. Assim, Romans, Petrus e Trilla (2003, p. 90) ressaltam que

[...] a educação social, ou a pedagogia gerontológica, pode oferecer a aquisição de novas habilidades e técnicas de aprendizagem, principalmente se se leva em conta que as pessoas idosas utilizam, com freqüência, habilidades não adaptadas ao meio educativo atual.

Como afirma Oliveira (1999), a ideia de que a educação é um processo permanente e que a aprendizagem dura a vida inteira é fruto não só da evolução histórica do pensamento sobre a educação, mas também da necessidade de uma educação contínua, que atenda às situações de mudança e, ainda, possibilite a maturação do indivíduo. 
Assim, para que o idoso possa estar diretamente em contato com novas possibilidades de aprendizagem, é fundamental que esteja inserido num processo educacional, havendo a mediação de conhecimentos para a estruturação da formação contínua do indivíduo como ser social.

Busca-se analisar como as políticas públicas possibilitam o acesso do idoso ao contexto educacional, não apenas o incluindo em uma modalidade de ensino, mas estabelecendo um espaço próprio, uma vez que ele tem seu próprio ritmo de aprendizagem e suas necessidades educacionais.

Observa-se que as políticas públicas voltadas à educação não amparam exclusivamente a educação para a faixa etária da terceira idade. Em legislações educacionais, o idoso é compreendido como adulto, não sendo consideradas suas necessidades educacionais específicas. O idoso encontra-se incluso em legislações específicas da modalidade da educação de jovens e adultos. Nas Diretrizes Curriculares Nacionais para a Educação de Jovens e Adultos (parecer CEB n ${ }^{\circ} 11 / 2000$ ), o idoso é citado, porém dentro desta modalidade.

Apesar de haver nas leis $\mathrm{n}^{\circ}$ 8.842/1994 e $\mathrm{n}^{\mathrm{a}} 10.741 / 2003$ um destaque ao direito à educação, pode-se destacar a ausência de uma legislação que contemple e ampare de maneira ativa o idoso no âmbito educacional.

A esfera governamental precisa cumprir com sua função de responsabilidade social, sendo a decisão do poder público de proporcionar ações comunitárias na região em que está presente e minorar possíveis danos provenientes de discriminações da faixa etária. Responsabilidade social é entendida aqui como um compromisso do poder público em relação à sociedade em geral e uma forma de prestação de contas do seu desempenho. Entre os vetores da responsabilidade social estão o apoio ao desenvolvimento da comunidade onde atua, a preservação do meio ambiente, a satisfação e investimento no bem-estar dos indivíduos. Tendo a terceira idade uma realidade da população brasileira, compete-lhe também assumir esse compromisso social com essa parcela da população que contribuiu para a sua formação. Porém, não pode ser considerado um ato de assistencialismo; antes, deve ser encarado como de solidariedade e de justiça social, além de retorno da dívida social para com a sociedade mais ampla, que utilizou da capacidade de trabalho de pessoas físicas que hoje são integrantes dessa faixa etária.

Ao exercitar seu papel social, o homem utiliza suas perspectivas de cidadania, que, para ser efetivamente exercitada, exige a capacidade de analisar e compreender a realidade, de criticá-la e atuar sobre ela. Porém, para essa nova realidade ser delineada se faz necessário um novo olhar, globalizado, sobre o processo de envelhecimento e o apoio da sociedade civil e pública para que se realizem ações preventivas, permitindo a construção de uma nova realidade.

Os direitos dos idosos, negligenciados há tempos, estão diante da possibilidade de serem entendidos e atendidos. Segundo Fernandes (apud DEBERT, 1999, p. 92), "pode-se reconhecer que 
há poucas leis relacionadas à defesa dos idosos. Mas é imperioso aceitar que o conteúdo da lei $\mathrm{n}^{\circ} 8.842 / 1994$, de 4 de janeiro de 1994, representa uma síntese do arcabouço jurídico vigente que valida as intenções manifestas do art. $230 \mathrm{da}$ Constituição Federal”. Para a divulgação dessa lei é imprescindível que haja a consciência dos legisladores, pois não se podem desrespeitar as reivindicações e exigências da população brasileira mais velha.

Observa-se, então, que as pessoas idosas estão começando a ser percebidas como seres pensantes, que têm muito para nos ensinar, porém ainda tem muito a aprender, demonstrando o quanto possuem a necessidade de sempre estar em contato com novos conhecimentos e novas experiências.

Apesar dessa notável mudança, ainda é possível perceber o quanto os idosos tendem a ser marginalizados pela sociedade. Além disso, as próprias políticas públicas muitas vezes se excluem do papel de inclusão dessas pessoas, tanto nos âmbitos políticos, como nos sociais e culturais.

\section{Materiais e métodos}

A presente investigação utilizou para coleta de dados aplicação de questionários para idosos que frequentam a Universidade Aberta para a Terceira Idade (Uati) da Universidade Estadual de Ponta Grossa. Os entrevistados têm idade entre 53 e 74 anos, sendo um homem e 17 mulheres, perfazendo um total de 18 alunos.
As questões do instrumento são relativas à qualidade de vida das pessoas que participam de programas e projetos educacionais, como a Uati, além de fazerem referência a posicionamentos pessoais sobre como estes programas podem auxiliar no desenvolvimento educacional, social e emocional dos idosos. Outro ponto refere-se à necessidade de abordar as razões e objetivos pelos quais essas pessoas ingressam e frequentam a Universidade Aberta para a Terceira Idade.

\section{Resultados}

$\mathrm{Na}$ tentativa de tornar a educação na terceira idade um projeto mais democrático, diversas teorias apontam que é preciso que cada estabelecimento de ensino tenha autonomia para gestar e gerir seu trabalho de acordo com o contexto em que está inserido; além de também poder realizar análises referentes à qualidade de vida. Entende-se que é necessário possibilitar aos idosos espaços para o crescimento e para a mudança, tanto em aspectos de cunho educacional como nos aspectos diretamente relacionados à pessoa em si.

Nos questionários analisados pode-se observar que, em relação à modificação na qualidade de vida depois do ingresso na Universidade Aberta para a Terceira Idade da Universidade Estadual de Ponta Grossa, houve unanimidade nas respostas afirmativas, pois todos os alunos consideram que ocorreram mudanças, como um melhor condicionamento para a realização de atividades diárias, como escovar os dentes, pentear os cabelos, 
tomar banho, calçar os sapatos, até melhoria na qualidade das relações pessoais, na família ou no círculo de convívio. Também foi observado que a diminuição do uso de medicamentos foi citada por quatro idosos.

Com base nesses dados, é possível observar que, quando os idosos começam a frequentar diferentes espaços, há a possibilidade de mudança. A respeito, parafraseando Thurler (2001, p. 21), nota-se que o sentido da mudança é uma construção individual, coletiva e interativa que ninguém pode fazer em lugar dos interessados, pois tem uma lógica própria e varia em função das culturas dos atores, das relações sociais em que estão envolvidos e das transações que se estabelecem entre eles a propósito de uma mudança projetada.

Portanto, nessa perspectiva todos os envolvidos devem pensar no coletivo para que se possa construir um ambiente diferente e dinâmico, onde haja espaço para discussões, conversas e trocas de experiências, visando, assim, a uma melhor qualidade de vida para todos os envolvidos.

Outro aspecto abordado faz referência à questão da importância das universidades abertas para a terceira idade, observando se esta proposta é válida para os seus envolvidos.

Neste ponto, também houve um consenso nas respostas, pois as 18 pessoas que responderam à pergunta "Você considera que as Universidades Abertas para a Terceira Idade apresentam uma proposta válida para os seus envolvidos?" concordaram que as Uatis são propostas válidas. Com base nessas respostas, conclui-se que os projetos referentes às universidades abertas para a terceira idade possuem uma proposta viável de melhoria na qualidade de vida, além de proporcionarem a possibilidade de interação e aquisição de novos conhecimentos.

Neste ponto, o entrevistado A6 relata: "Comecei a frequentar a UATI para interagir com mais pessoas de minha idade, estabelecer novas amizades e adquirir conhecimentos." Com este depoimento e muitos outros, pode-se afirmar que esses projetos realmente são válidos e trazem a possibilidade de mudança na vida dos idosos envolvidos.

Outro questionamento também analisado refere-se ao fato de terem ocorrido ou não mudanças comportamentais nos idosos a partir do momento em que começaram a participar da Uati/UEPG. Nem todos os entrevistados consideram que o ingresso na Uati levou-os a terem outros comportamentos, pois, ao responderem à questão "Você considera-se uma pessoa com mais vez e voz depois que ingressou na Uati/UEPG?", somente 16 afirmaram que sim.

Apesar de duas pessoas demonstrarem que não houve mudança comportamental, a maioria afirma que, a partir do momento em que começaram a frequentar a Uati, puderam notar mudanças em suas vidas, tendo mais espaço na sociedade.

Após analisar essas questões, como também a fala dos entrevistados através do questionário, foi possível observar que a educação continuada na terceira idade tem a possibilidade de trazer diversas melhorias tanto nos aspectos sociais 
como nos aspectos emocionais dessas pessoas, possibilitando-lhes uma melhor qualidade de vida.

Por meio de alguns relatos foi possível confirmar essa afirmação, pois, como diz o entrevistado A12: "Posso aprender, melhorar a saúde, não ter mais solidão. Vivendo em grupo, me divirto e sou feliz." Para o entrevistado A10, ele começou a frequentar a UATI "para melhor qualidade de vida, onde passei a ter amigos e várias atividades". Já em outro relato, de A17, o entrevistado afirmou que "por incentivo de pessoas que já frequentam a UATI estou aqui, e pelo testemunho de uma mente aberta, inteligente e um sorriso aberto de felicidade, sabendo enfrentar os obstáculos do dia a dia”.

\section{Discussão}

É preciso rever como o idoso está sendo percebido e aceito na sociedade e como está presenciando estas mudanças no espaço político-social e em sua própria vida. Com essa análise torna-se pautável compreender como a educação poderá modificar esse quadro vivenciado em nossa sociedade há muitos anos.

Dessa maneira, o papel da educação nessa realidade torna-se fundamental, pois é por meio dela que as heranças culturais presentes em nossa realidade poderão se modificar no pensamento da população.

Observa-se o quanto as pessoas se prendem às ideologias que permeiam todo pensamento e aspectos culturais, tornando complexo compreender esse pensamento e, assim, revertê-lo. Por- tanto, é preciso auxiliar as pessoas nesta transformação, pois apenas desta maneira será possível reverter muitos problemas sociais, em especial a exclusão do idoso na sociedade. Nesse aspecto, Freire (1996, p. 110) aponta que "a educação é uma forma de intervenção no mundo".

Torna-se imprescindível rever as estruturas que permeiam a educação, para que se possam redirecionar os aspectos excludentes da nossa cultura. Neste âmbito, é preciso ressaltar o papel democrático que a educação possui por todas as possibilidades de mudança que podem ocorrer por meio dela.

\section{Conclusão}

Com a pesquisa sobre a educação na terceira idade pretende-se integrar cada vez mais o idoso a uma educação continuada, possibilitando uma maior satisfação pessoal, com a amplitude de atividades, além de proporcionar-lhe uma melhor qualidade de vida.

Almeja-se oferecer atividades e reflexões sobre a educação continuada na terceira idade, além de buscar, juntamente com os professores e alunos da Uati/UEPG, alternativas de melhorias para o projeto em que estão envolvidos, auxiliando os idosos a compreenderem o grande papel social que possuem, pois são indispensáveis na sociedade como um todo. 
Social change and learning: the role of education in the third age

\section{Abstract}

It is observed that people in the seniors have much to teach, but still has a lot to learn, demonstrating the need to be in touch with new knowledge and also new experiences. The elderly have the right to education, provided for in chapter $\mathrm{V}$, in articles 20 to 25 of the Statute of the Elderly (law $10.741 / 2003)$. Thus, this research has as its objective to identify the role of education as a possibility for change for the elderly; analyze the different forms of inclusion and integration of the elderly in the educational context, examine public policies aimed at the elderly right to education. The research is quantitative, qualitative, used the observation and implementation of questionnaires to students of the Open University for the Third Age UEPG for data collection. As a result, it was possible to observe an action that allows conscious educational changes and transformations in the lives of the elderly, enabling a better quality of life. As well as public policies geared to that segment should provide rights in various fields such as health, leisure, sport and education.

Key words: Elderly. Public police. Education. Continuing.

\section{Referências}

ALBOM, M. A última grande lição: o sentido da vida. 6. ed. Rio de Janeiro: Sextante, 1998. BACELAR, R. Envelhecimento e produtividade: processos de subjetivação. 2. ed. Recife: Fundação Antônio dos Santos Abranches, 2002.

CASTRO, O. P. Envelhecer: um encontro inesperado? Sapucaí do Sul: Notadez, 2001.
DEBERT, G. G.; NERI, A. L. (Org.). Velhice e sociedade. Campinas: Papirus, 1999.

FERNANDES, F. As pessoas idosas na legislação brasileira: direito e gerontologia. São Paulo: LTR, 1997

FREIRE, P. Educação e mudança. São Paulo: Paz e Terra, 1979.

. Pedagogia da autonomia. São Paulo: Paz e Terra, 1996.

MINAYO, M. C. Pesquisa social: teoria, método e criatividade. Petrópolis: Vozes, 1994.

MORAGAS, R. M. Gerontología social: envejecimiento y calidad de vida. Barcelona: Herder, 1991.

PICONEZ, S. Educação escolar de jovens e adultos. São Paulo: Paulinas, 2002.

OLIVEIRA, R. C. S. Terceira idade: do repensar dos limites aos sonhos possíveis. Campinas: Papirus, 1999.

ROMANS, M.; PETRUS, A.; TRILLA, J. Profissão educador social. Porto Alegre: Artmed, 2003.

SAVIANI, S. Pedagogia histórico-crítica. Campinas: Autores Associados, 2003.

SCHONS, C. R.; PALMA, L. T. S. Conversando com Nara Costa Rodrigues sobre a gerontologia social. Passo Fundo: UPF, 2000.

SOUZA, S. Sexualidade e amor na velhice. Porto Alegre: Sulina, 2003.

VIEIRA PINTO, A. Sete lições sobre a educação de adultos. São Paulo: Cortez, 1989. 